\title{
Modelisation of Membrane Distillation: Mass and Heat Transfer in Air Gap Membrane Distillation
}

\author{
Rochd S*, Zerradi H, Mizani S, Dezairi A and Ouaskit S \\ Laboratory of Physics of Condensed Matter (URAC10), Ben M'sik Sciences, University Hassan II Casablanca, Morocco
}

\begin{abstract}
Membrane distillation (MD) is receiving recent attention as a technique to efficiently concentrate aqueous solution such as seawater. It has potential benefits of low temperature and pressure operation with high degrees of separation. In this work, the effect of the membrane thickness was studied to produce of the steam flow in the three different mass transfer mechanisms, and in the different possible combinations of its mechanisms in three different temperatures. The results have been carried using a polynomial approximation through MATLAB. A quite important increase in the flow in the model (DGM, Schofield, and KMPT) was observed with a decrease in the stream rating in the model (KMT). However, the Molecular model, DGM model, KMPT model, and Schofield model are not affected by the membrane's thickness. After, we have studied the effect of this parameter (Thickness of the membrane) on the transfer of conduction heat and latent heat.
\end{abstract}

Keywords: Membrane; Distillation; AGMD; Diffusion; Thickness

\section{List of Symbols}

Local permeate flux at the hot side of membrane in vapor

phase $\left[\mathrm{Kg} / \mathrm{m}^{2} . \mathrm{s}\right]$

$\varepsilon \quad$ Porosity of the membrane

$\mathrm{T}$ Tortuosity

$\gamma_{p} \quad$ Membrane pore size $[\mathrm{m}]$

$M_{v} \quad$ Molar mass $[\mathrm{Kg} / \mathrm{mol}]$

$\mathrm{R} \quad$ Universal gas constant [J/mol.K]

$T_{m} \quad$ Average temperature of the membrane $\left[{ }^{\circ} \mathrm{C}\right]$

$P_{m} \quad$ Average pressure partial of the air $\left[\mathrm{P}_{\mathrm{a}}\right]$

$\delta_{m} \quad$ Thickness of the membrane [m]

$\mathrm{P} \quad$ Pressure $\left[\mathrm{P}_{\mathrm{a}}\right]$

$D_{v / a} \quad$ Diffusion coefficient of the vapor in the vapor/air mixture

$D_{v / a} \quad\left[\mathrm{~m}^{2} / \mathrm{s}\right]$

$\mu \quad$ Dynamic viscosity $[\mathrm{Kg} / \mathrm{m} . \mathrm{s}]$

$P_{v} \quad$ Water vapor pressure $\left[\mathrm{P}_{\mathrm{a}}\right]$

$C_{s} \quad$ Mole fraction of $\mathrm{NaCl}$

$\mathrm{hm} \quad$ Hot liquid/ membrane interface

M Membrane

mg Membrane/ air gap interface

S Saline

P Pores

v/a Vapor/air

$C_{1} \quad$ Concentration in the feed part

$\mathrm{C}_{2} \quad$ Concentration in the air gap part

$\mathrm{K}$ Transfer coefficient $[\mathrm{m} / \mathrm{s}]$

$D_{\text {eff }} \quad$ Effective diffusion coefficient $\left[\mathrm{m}^{2} \mathrm{~s}^{-1}\right]$

$R_{e} \quad$ Reynold number of the hot solution channel

$P_{r} \quad$ Prandlt number

$d_{h} \quad$ Half-width of the flow channel [m]

$H_{m} \quad$ Membrane length [m]

$T_{g f} \quad$ Temperature at the interface of hot feed and the membrane $\left[{ }^{\circ} \mathrm{C}\right]$
$T_{f} \quad$ Feed bulk temperature $\left[{ }^{\circ} \mathrm{C}\right]$

$T_{c} \quad$ Bulk temperature of the coolant $\left[{ }^{\circ} \mathrm{C}\right]$

$Q_{s} \quad$ Total heat $\left[\mathrm{KJ} / \mathrm{m}^{2} \mathrm{~h}\right]$

$Q_{c} \quad$ Flow of heat by conduction $\left[\mathrm{KJ} / \mathrm{m}^{2} \mathrm{~h}\right]$

$Q_{v} \quad$ Latent heat flux $\left[\mathrm{KJ} / \mathrm{m}^{2} \mathrm{~h}\right]$

$R_{m} \quad$ Gas constant of membrane $[\mathrm{J} / \mathrm{mol} \mathrm{K}]$

$K_{c m} \quad$ Thermal conductivity of the materiel forming the membrane $[\mathrm{W} / \mathrm{m} . \mathrm{K}]$

$K_{a} \quad$ Thermal conductivity of air [W/m.K]

$K_{m} \quad$ Thermal conductivity of membrane [W/m.K]

$J_{v} \Delta h_{v} \quad J_{v} \Delta h_{v}$ Enthalpy of hot solution $[\mathrm{J} / \mathrm{Kg}]$

$T_{h} \quad$ Hot temperature $\left[{ }^{\circ} \mathrm{C}\right]$

\section{Introduction}

In the early of 1980 with the growth of membrane engineering, MD claims to be a cost effective separation process that can utilize low-grade waste and alternative energy sources such as solar and geothermal energy [1]. Membrane distillation is a hybrid process that uses membranes and operates based on evaporation. Unlike most other membrane process, $\mathrm{MD}$ does not require a mechanical pressure pump and is not limited by the osmosis pressure [2].

A variety of methods may be employed in MD, such as direct contact membrane distillation (DCMD) in which the membrane is

*Corresponding author: Rochd Sanaa, Faculty of Ben M'sik Sciences, Laboratory of Physics of Condensed Matter (URAC10), University Hassan II Casablanca, Morocco, E-mail: rochd.sanaa91@gmail.com

Received May 11, 2016; Accepted June 09, 2016; Published June 16, 2016

Citation: Rochd S, Zerradi H, Mizani S, Dezairi A, Ouaskit S (2016) Modelisation of Membrane Distillation: Mass and Heat Transfer in Air Gap Membrane Distillation. J Membra Sci Technol 6: 154. doi:10.4172/2155-9589.1000154

Copyright: @ 2016 Rochd S, et al. This is an open-access article distributed under the terms of the Creative Commons Attribution License, which permits unrestricted use, distribution, and reproduction in any medium, provided the original author and source are credited. 
in direct contact with liquid phases in both sides [3-5]. Then, air gap membrane distillation (AGMD) in which an air layer is interposed between the membrane and the condensation surface [6,7]. At that time, a vacuum membrane distillation (VMD) where, a vacuum is applied to increase or establish the vapor pressure difference between the membrane sides and the condensation takes place in an external condenser $[8,9]$. At that point, sweeping gas membrane distillation (SGMD) in which a stripping gas is used on the cold side to sweep the permeate away, with Condensation in a separate device [10-14]

At this juncture, it is worthwhile to underline that the membrane technique is considered promising since it takes place at temperatures range (30 to 90$)^{\circ} \mathrm{C}$ and can use solar energy [15]. A survey of the stateon-the-art of membrane distillation (MD) and its various and detailed applications was presented by Alklaibi and Lior [16]. Not far, Ding et al. presented a model for predicting the rate of mass transfer in a membrane distillation unit to direct contact (DCMD) [17]. Other researchers, including Meindersma [18], Guijt [19], Payo [14], and Chouikh [20,21] worked on AGMD, but none of them used solar as the energy source. Likewise, Mandiang [22-24] have studied three different types of mass transfer modes through the membrane and possible combinations of this type. Also, Morteza Asghari [23] studied the effect of the thickness of the membrane in transfer mechanism of Knudsen [23].

Our contribution is to redo the results of Mandiang and use them to study the effect of the thickness of the membrane on the production of the steam flow in the three different mass transfer mechanisms, and in different possible combinations of its mechanisms. After, we have studied the effect of this parameter (Thickness of the membrane) on the transfer of conduction heat and latent heat.

\section{Definition of the Method}

In air-gap $\mathrm{MD}$, the evaporator channel resembles that in DCMD, whereas the permeate gap lies between the membrane and a cooled walling and is filled with air. The vapor passing through the membrane must additionally overcome this air gap before condensing on the cooler surface. The advantage of this method is the high thermal insulation towards the condenser channel, thus minimizing heat conduction losses. However, the disadvantage is that the air gap represents an additional barrier for mass transport, reducing the surface- related permeate output compared to DCMD. A further advantage towards DCMD is the fact, that volatile substances with a low surface tension, such as alcohol or other solvents can be separated from diluted solutions, due to the fact that there is no contact between the liquid permeate and the membrane with AGMD (Figure 1). A temperatures range of system: $\left.T_{h m}=40^{\circ} \mathrm{Cto} 80^{\circ} \mathrm{C}\right)$ and $\left(T_{m g}=10^{\circ} \mathrm{C}\right.$ to $\left.30^{\circ} \mathrm{C}\right)[24]$.

\section{Mechanism of Mass Transfer}

The three types of mechanisms of Mass transfer are:

Knudsen diffusion (based on collisions between molecules and thewall) [24]

This type of distribution is important in systems with high temperature and pressure.

$J_{K}=K_{K}\left(P_{h m}-P_{m g}\right)$

With: $\quad K_{k}=\frac{2}{3} \frac{\varepsilon}{\tau} \frac{r_{P}}{\delta_{m}} \sqrt{\frac{8 M_{v}}{\pi R T_{m}}}$

Molecular diffusion (based on collision between molecules) [24]
This type of distribution is important in systems of intermediate temperature and pressure.

$J_{M, \mathrm{~S}}=K_{M, S}\left(P_{h m}-P_{m g}\right)$

With: $K_{M, S}=\frac{\varepsilon p D_{v / a} M_{v}}{\tau \delta_{m} R T_{m} P_{a}}$

Viscous diffusion (based on both types of collisions) [24]

This type of distribution is important in systems of low temperature and pressure.

$J_{p}=K_{M, S} \Delta P_{v}$

With: $K_{p}=\frac{1}{8 \gamma_{g}} \frac{r_{p}^{2} \varepsilon}{\tau} \frac{P_{m} M_{v}}{\delta_{m} R T_{m}}$

In order to explain the reduction of vapor pressure caused by the dissolved species, Raoul's law [25] may be used.

$P_{h m}=\left(1-C_{s}\right) p_{v}$

Where $C_{s}$ is the mole fraction of solute or salinity? The difference in partial pressure of the saturated vapor of both sides of the membrane may be calculated from the law of Antoine [15] using the following equation:

$$
\mathrm{p}_{\mathrm{v}}=\exp \left(23.328-\frac{3841}{\mathrm{~T}-45}\right)
$$

The average temperature of the membrane is given by the following equation [22]

$$
T_{m}=\frac{T_{h m}+T_{m g}}{2}
$$

Furthermore Qtaishat et al. proposed the expression amount of the steam/air:

$\mathrm{PDv} / \mathrm{a}\left(\mathrm{Pa} \cdot \mathrm{m}^{2} . \mathrm{s}^{-1}\right)$ depending on the temperature [26]

$$
P D_{v / a}=1.985 .10^{-5} T^{2.072}
$$

\section{Modes Combination of Three Flows}

\section{DGM model}

The model "Dusty Gas" (DGM) shown in Figure 2. In this model, the coefficient of permeability of the membrane due to molecular

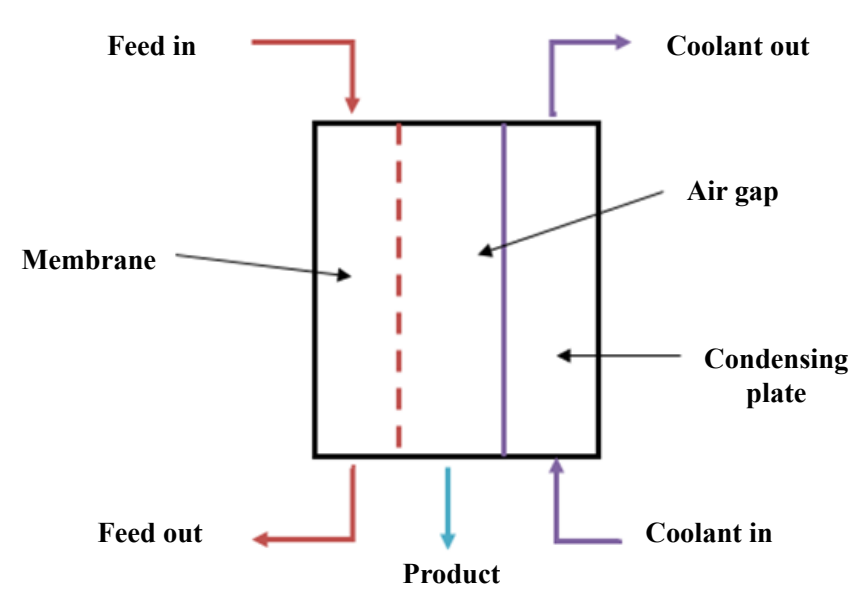

Figure 1: Principe of operation of the AGMD. 
Citation: Rochd S, Zerradi H, Mizani S, Dezairi A, Ouaskit S (2016) Modelisation of Membrane Distillation: Mass and Heat Transfer in Air Gap Membrane Distillation. J Membra Sci Technol 6: 154. doi:10.4172/2155-9589.1000154

Page 3 of 9

diffusion and of Knudsen are combined as resistance in series, where in the potential drops (pressure difference) are additive [22].

$$
J_{D G M}=\frac{\left(J_{M, \mathrm{~S}}+J_{K}\right) \mathrm{J}_{P}}{J_{M, S}+J_{K}+J_{P}}
$$

\section{Schofield model}

In this model, the coefficient of diffusion of Knudsen and Poiseuille are parallel and in series with the Fick's flow (Figure 3) [22].

$$
J_{\text {Schofield }}=\frac{J_{K} \mathrm{~J}_{P}}{J_{K}+J_{P}}+J_{M, S}
$$

\section{KMPT model}

In this model, the diffusion co-efficient of Molecular Knudsen are in parallel and in series with the poiseuille (Figure 4) [22].

$$
J_{K M P T}=\frac{J_{K} \mathrm{~J}_{M, S}}{J_{K}+J_{M, S}}+J_{P}
$$

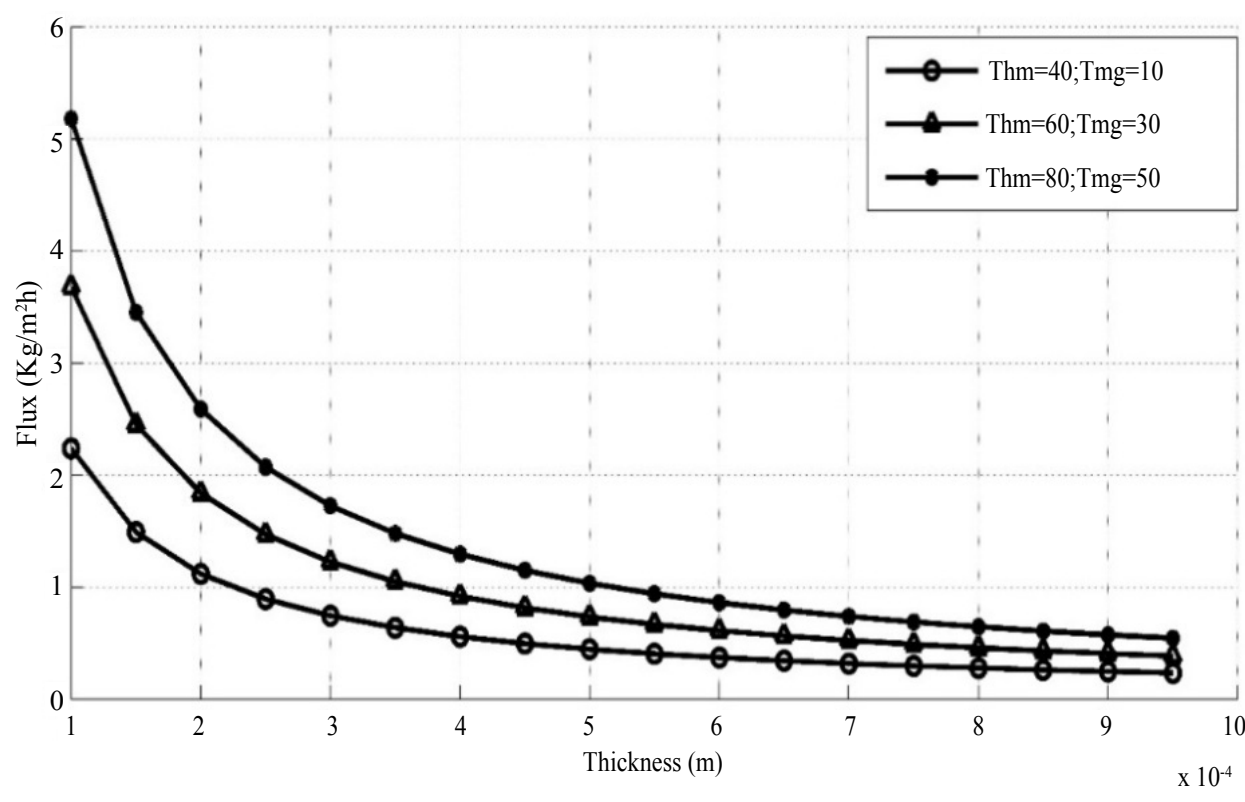

Figure 2: Mass transfer of Knudsen Diffusion according to the membrane thickness in three different temperatures.

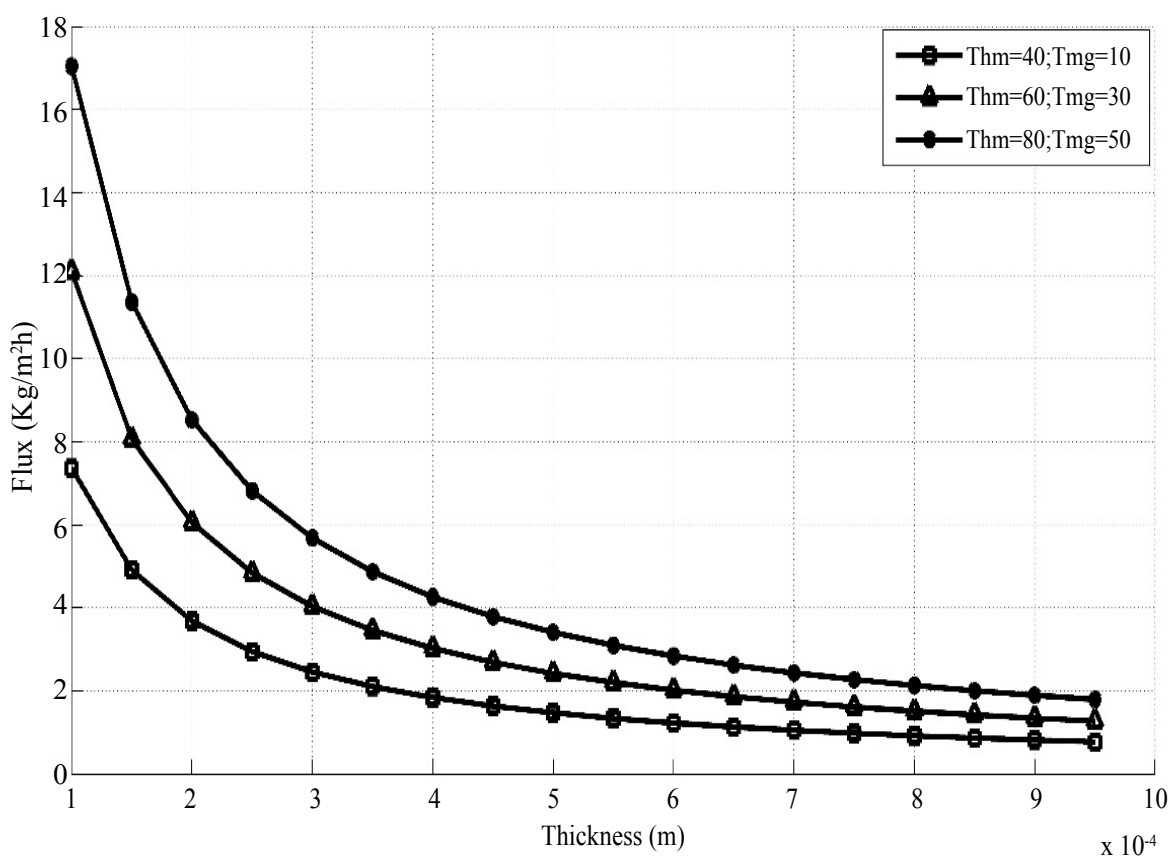

Figure 3: Mass transfer of viscous diffusion according to the membrane thickness in three different temperatures. 


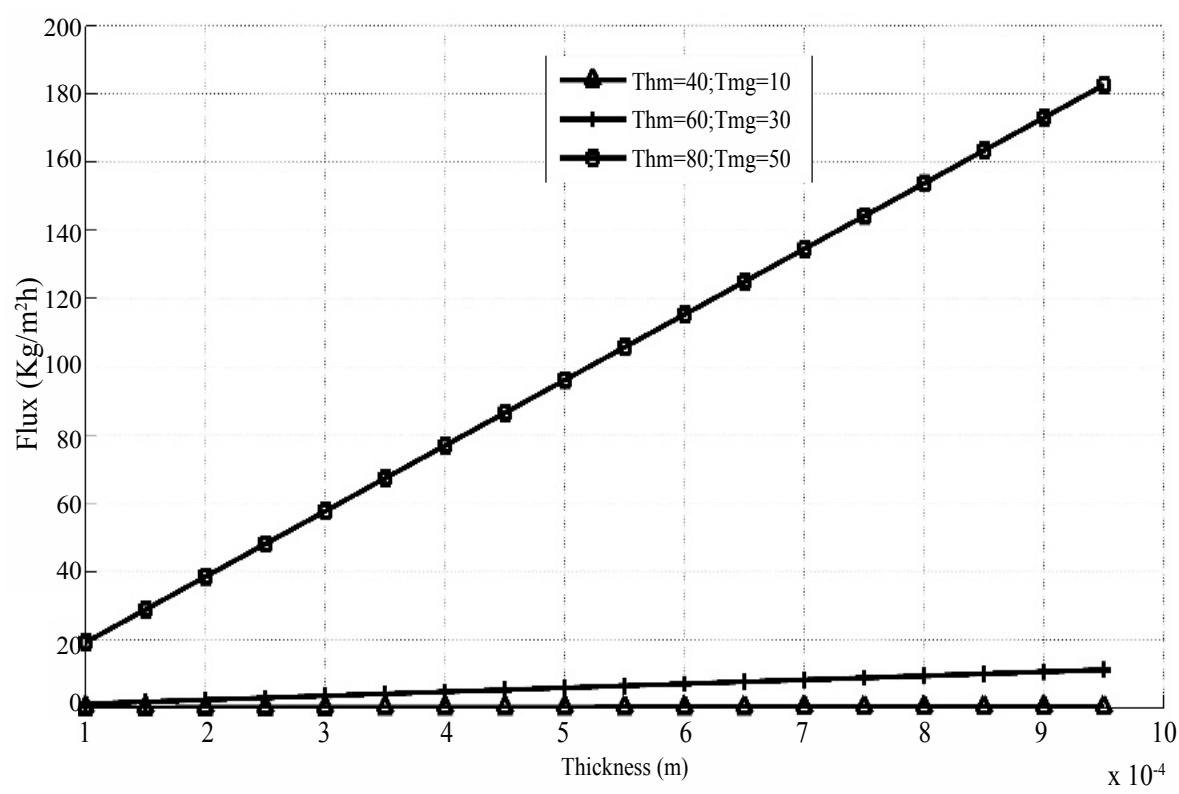

Figure 4: Mass transfer of Molecular Diffusion according to the membrane thickness in three different temperatures.

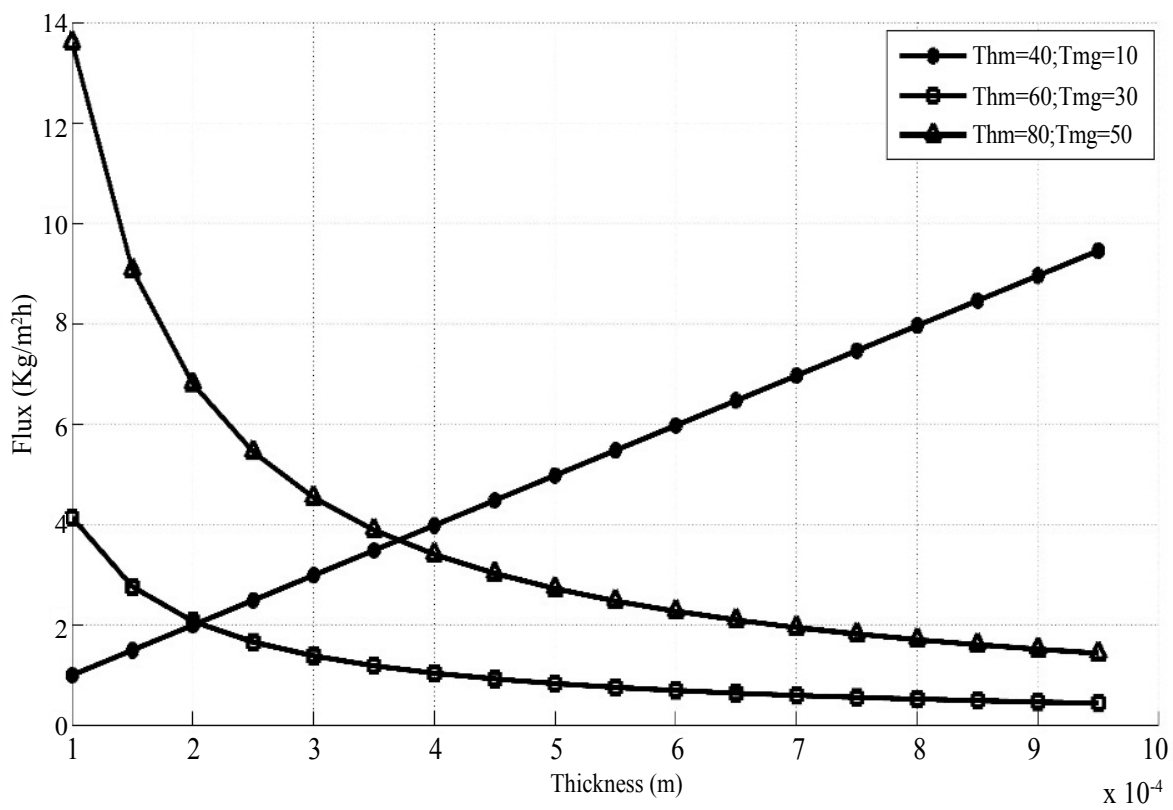

Figure 5: Mass transfer of three different types of diffusion according to the membrane thickness at $h=60^{\circ} \mathrm{C}$ and $=25^{\circ} \mathrm{C}$.

\section{KMT model}

In this model, the Knudsen and Molecular flows are in parallel (Figure 5) [22].

$$
J_{K M T}=\frac{J_{K} \mathbf{J}_{M, S}}{J_{K}+J_{M, S}}
$$

\section{Transfer of Heat Flow}

Two main heat transfer mechanisms occur in the MD system: Latent heat and conduction heat transfer [27]:
$Q_{S}=Q_{C}+Q_{v}$

The flow of heat by conduction $\left(Q_{C}\right)$ is defined by:

$Q_{C}=\frac{T_{h m}+T_{m g}}{R_{m}}=\frac{k_{c m}}{\delta_{m}}\left(T_{h m}-T_{m g}\right)$

The thermal conductivity of the membrane $k_{c m}$ is defined by the equation as:

$$
k_{c m}=\varepsilon k_{a}+(1-\varepsilon) k_{m}
$$

Where: 
$k_{m}$ : Thermal conductivity of the materiel forming the membrane.

$k_{a}$ : Thermal conductivity of air.

The latent heat flux $\left(Q_{v}\right)$ of the vapor through the membrane is defined by:

$$
Q_{v}=J_{v} \Delta h_{v}
$$

Where $J_{v} \Delta h_{v}$ : Enthalpy of unit mass of steam $(\mathrm{J} / \mathrm{Kg})$.

The temperature of the hot vapor side of the membrane is defined by:

$$
T_{h m}=\frac{h_{h} T_{h}-J_{v} \Delta h_{v}+\frac{k_{c m}}{\delta_{m}} T_{m g}}{h_{h}+\frac{k_{c m}}{\delta m}}
$$

Where the convection coefficient steady correlation is given by the creatz-leveque:

$$
h_{h}=1.86\left(\mathrm{R}_{e} P_{r} \frac{d_{h}}{H_{m}}\right)^{0.33}
$$

The total transfer across the membrane $\left(Q_{s}\right)$ is:

$\tilde{Q}_{S}=\tilde{Q}_{v}+\tilde{Q}_{C}$

Where the $\mathrm{x}$-average conductive heat transfer is:

$$
\tilde{Q}_{C}=\frac{1}{l_{m}} \int_{0}^{l_{m}} Q_{c}(x) d x
$$

Moreover, the $\mathrm{x}$-average latent heat flux is:

$$
\tilde{Q}_{v}=\frac{1}{l_{m}} \int_{0}^{l_{m}} Q_{v}(x) d x
$$

\section{Temperature De Polarization}

This temperature variation across the membrane can be describe by the temperature polarization factor (TPC) that is defined as [28]:

$$
T P C=\frac{T_{h m}-T_{g f}}{T_{f}-T_{c}}
$$

Where: $T_{h m}$ is the temperature at the interface of hot feed and the membrane $\left({ }^{\circ} \mathrm{C}\right), T_{\text {of }}$ is the temperature at the interface of hot feed and the membrane $\left({ }^{\circ} \mathrm{C}\right), T_{f}$ is feed bulk temperature $\left({ }^{\circ} \mathrm{C}\right), T_{c}$ is bulk temperature of the coolant $\left({ }^{\circ} \mathrm{C}\right)$.

\section{Results and Discussion}

Simulation were carried with the following input data: $\mathrm{k}_{\mathrm{m}}=0.05 \mathrm{~W} . \mathrm{m}$ ${ }^{1} \cdot \mathrm{K}^{-1} ; \mathrm{l}_{\mathrm{m}}=0.2 \mathrm{~m} ; \mathrm{H}_{\mathrm{m}}=0.2 \mathrm{~m} ; \mathrm{d}_{\mathrm{h}}=0.002 \mathrm{~m} ; \operatorname{Pr}=7.2 ; \mathrm{Re}=192 ; \mathrm{ka}=60 \mathrm{~W} / \mathrm{m} . \mathrm{K}$. When the temperature is fixed at three different temperatures and the membrane thickness is swept between $\left[1.10^{-4}, 10.10^{-4}\right] \mathrm{m}$, following results are observed: Prior to undertaking detailed presentation and discussion of the new results obtained in this study, Figure 2 shows the variation of the vapor of Knudsen diffusion as function of the membrane thickness in three different temperature. In this figure, the decrease of the flux is seen by increasing the thickness such as the flow begins to decrease from the value $\left(1.10^{-4} \mathrm{~m}\right)$ and becomes constant when the value of the thickness of the membrane exceeds $\left(9.10^{-4} \mathrm{~m}\right)$, the maximum value of flux is $\left(4.25 \mathrm{~kg} / \mathrm{m}^{2} \mathrm{~h}\right)$. However, we have seen for the temperature $\left(T_{h m}{ }^{\circ} \mathrm{C}, T_{m g}=50^{\circ} \mathrm{C}\right.$ a bigger flow of steam production compared to the case temperature $\left(T_{h m}=60^{\circ} \mathrm{C}, T_{m g}=30^{\circ} \mathrm{C}\right)$ and $\left(T_{h m}\right.$ $\left.=40^{\circ} \mathrm{C}, T_{m g}=10^{\circ} \mathrm{C}\right)$, as in some cases of temperature $\left(T_{h m}=40^{\circ} \mathrm{C}, T_{m g}\right.$ $=10^{\circ} \mathrm{C}$ ), we have seen a very low vapor production.
This observation is in line with Figure 3, which shows the variation of the vapor of viscous diffusion as function of the membrane thickness in three different temperatures. In this figure, the flux decrease is seen by increasing the thickness, such as the flow begins to decrease from the value $\left(1.10^{-4}\right)$ and becomes constant when the value of the thickness of the membrane exceeds $\left(9.10^{-4}\right) \mathrm{m}$. the maximum value of flux is $(13.75$ $\left.\mathrm{Kg} / \mathrm{m}^{2} \mathrm{~h}\right)$. However, we have seen for the temperature $\left(T_{h m}=80^{\circ} \mathrm{C}\right.$, $T_{m g}=50^{\circ} \mathrm{C}$ ) a bigger flow of steam production compared to the case temperature $\left(T_{h m}=60^{\circ} \mathrm{C}, T_{m g}=30^{\circ} \mathrm{C}\right)$ and $\left(T_{h m}=40^{\circ} \mathrm{C}, T_{m g}=10^{\circ} \mathrm{C}\right)$, as in some cases of temperature $\left(T_{h m}=40^{\circ} \mathrm{C}, T_{m g}=10^{\circ} \mathrm{C}\right)$, we have seen a very low vapor production.

Figure 4 shows representative results on the variation of the vapor of molecular diffusion as function of the membrane thickness in three different temperatures. In this figure, an increase of flow depending on the thickness of the membrane of $\left(1.10^{-4}\right)$ to $\left(9.10^{-4}\right)$ is observed. However, we have seen for the temperature $\left(T_{h m}=80^{\circ} \mathrm{C}, T_{m g}=50^{\circ} \mathrm{C}\right) \mathrm{a}$ bigger flow of steam production compared to the case temperature $\left(T_{h m}=60^{\circ} \mathrm{C}, T_{m g}=30^{\circ} \mathrm{C}\right)$ and $\left(T_{h m}=40^{\circ} \mathrm{C}, T_{m g}=10^{\circ} \mathrm{C}\right)$, as in some cases of temperature $\left(T_{h m}=40^{\circ} \mathrm{C}, T_{m g}=10^{\circ} \mathrm{C}\right)$, we have seen a very low vapor production.

Now turning our attention to Figure 5, that shows the variation of the vapor of different transfer mechanisms as function of the membrane thickness. An observation for both mechanisms Knudsen and viscous (Figures 2-4), shows a rating decrease of flux depending on the membrane thickness because the thickness of the membrane increases the diffusion path which increases the mass transfer resistance and therefore reduces the flow. Rating decrease of the flow would suggest the weakness of the two mechanisms. For the molecular mechanism (Figures 4 and 5), it is observed, that the flow increases simultaneously with the thickness of the membrane because the molecular flow is strangest among the three types of Mass transfer mechanism in this field of temperature.

Figure 6 also indicates the variation of the vapor of DGM model as function of the membrane thickness in three different temperatures. In this figure, an increase simultaneously of the flow is depending on the thickness of the membrane of $\left(1.10^{-4}\right)$ to $\left(9.10^{-4}\right)$. However, we have seen for the temperature $\left(T_{h m}=80^{\circ} \mathrm{C}, T_{m g}=50^{\circ} \mathrm{C}\right)$ a bigger flow of steam production compared to the case temperature $\left(T_{h m}=60^{\circ} \mathrm{C}, T_{m g}=30^{\circ} \mathrm{C}\right)$ and $\left(T_{h m}=40^{\circ} \mathrm{C}, T_{m g}=10^{\circ} \mathrm{C}\right)$, as in some cases of temperature $\left(T_{h m}^{m g}=40^{\circ} \mathrm{C}\right.$, $T_{m g}=10^{\circ} \mathrm{C}$ ), we have seen a very low vapor production.

Figure 7 describes the variation of the vapor of Schofield model as function of the membrane thickness in three different temperatures. An increase of the flow is depending on the thickness of the membrane of $\left(1.10^{-4}\right)$ to $\left(9.10^{-4}\right)$. However, we have seen for the temperature $\left(T_{h m}=80^{\circ} \mathrm{C}, T_{m g}=50^{\circ} \mathrm{C}\right)$ a bigger flow of steam production compared to the case temperature $\left(T_{h m}=60^{\circ} \mathrm{C}, T_{m g}=30^{\circ} \mathrm{C}\right)$ and $\left(T_{h m}=40^{\circ} \mathrm{C}, T_{m g}=10^{\circ} \mathrm{C}\right)$, as in some cases of temperature $\left(T_{h m}=40^{\circ} \mathrm{C}, T_{m g}=10^{\circ} \mathrm{C}\right)$, we have seen a very low vapor production.

Figure 8 shows the variation of the vapor of KMPT model as function of the membrane Thickness in three different temperatures. In this figure, we show an increase simultaneously of flow depending on the thickness of the membrane of $\left(2 \cdot 10^{-4}\right)$ to $\left(9 \cdot 10^{-4}\right)$. However, we have seen for the temperature $\left(T_{h m}=80^{\circ} \mathrm{C}, T_{m g}=50^{\circ} \mathrm{C}\right)$ a bigger flow of steam production compared to the case temperature $\left(T_{h m}=60^{\circ} \mathrm{C}, T_{m g}=30^{\circ} \mathrm{C}\right)$ and $\left(T_{h m}=40^{\circ} \mathrm{C}, T_{m g}=10^{\circ} \mathrm{C}\right)$, as in some cases of temperature $\left(T_{h m}^{m g}=40^{\circ} \mathrm{C}\right.$, $T_{m g}=10^{\circ} \mathrm{C}$ ), we have seen a very low vapor production.

Another time Figure 9 shows the variation of the vapor of KMT model as function of the membrane Thickness in three different 


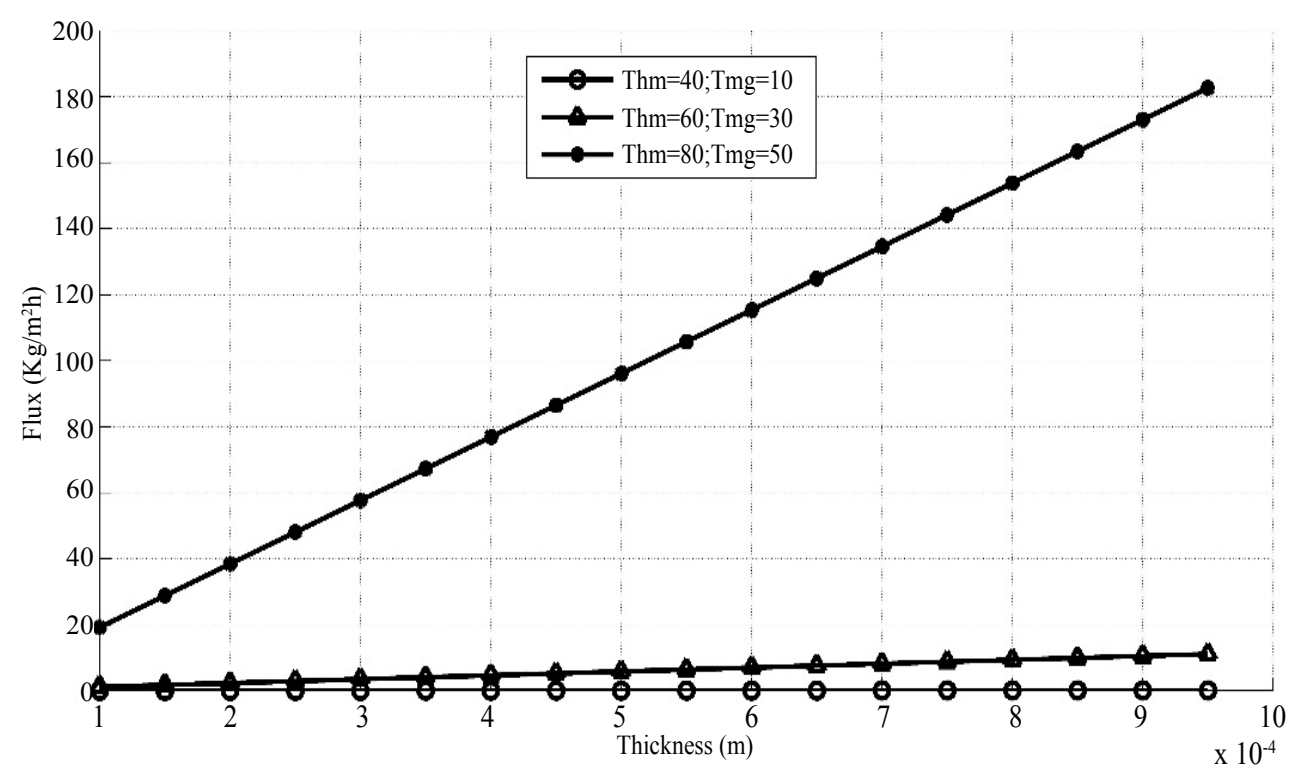

Figure 6: Evolution of Model "DGM" as function of membrane thickness in three different temperatures.

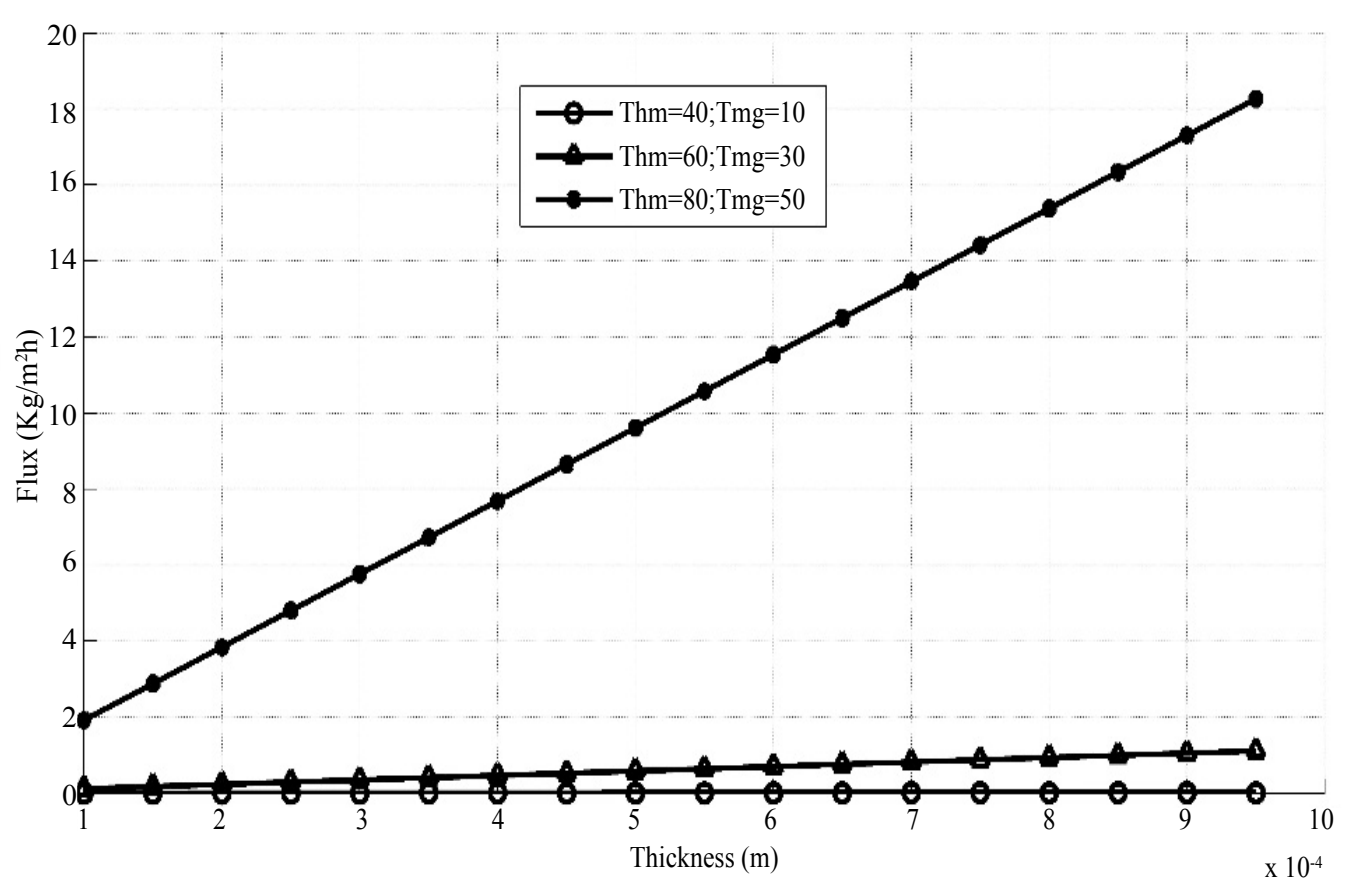

Figure 7: Evolution of Model "Schofiled" as function of membrane Thickness in three different temperature.

temperatures. In this figure, the flux decreases by increasing the thickness such as the flow begins to decrease from the value $\left(1.10^{-4}\right)$ and becomes constant when the value of the thickness of the membrane exceeds $\left(9.10^{-4}\right) \mathrm{m}$, the maximum value of flux is $4.25\left(\mathrm{~kg} / \mathrm{m}^{2} h\right)$, however, we have seen for the temperature $\left(T_{h m}=80^{\circ} \mathrm{C}, T_{m g}=50^{\circ} \mathrm{C}\right)$ a bigger flow of steam production compared to the case temperature $\left(T_{h m}=60^{\circ} \mathrm{C}, T_{m g}=30^{\circ} \mathrm{C}\right)$ and $\left(T_{h m}=40^{\circ} \mathrm{C}, T_{m g}=10^{\circ} \mathrm{C}\right)$, as in some cases of temperature $\left(T_{h m}=40^{\circ} \mathrm{C}, T_{m g}=10^{\circ} \mathrm{C}\right)$, we have seen a very low vapor production.
After, the thickness of the membrane is varied in the various possible combinations of flux transfer mechanism (Figures 6-9), an observation shows an increase in the flow in the model (Figures 6-8) and a stream rating decreases in the model (Figure 9). This also indicates that the increased flow as a function of the thickness by the following equation [29]:

$$
J=D_{e f f} \frac{C_{2}-C_{1}}{\delta_{m}}=\frac{D_{e f f}}{\delta_{m}}\left(C_{1}-C_{2}\right)=K\left(C_{1}-C_{2}\right)
$$




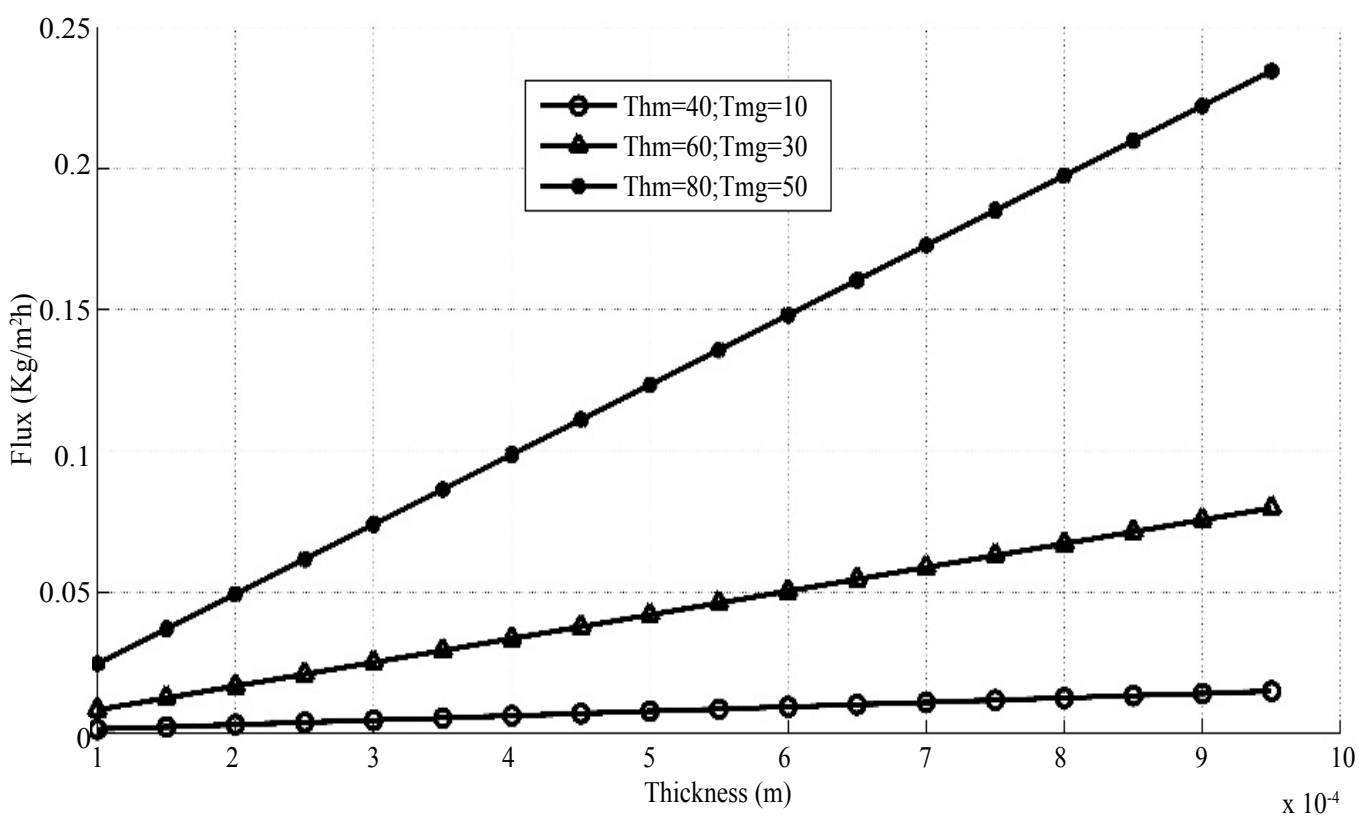

Figure 8: Evolution of model "KMPT" as function of membrane thickness in three different temperature.

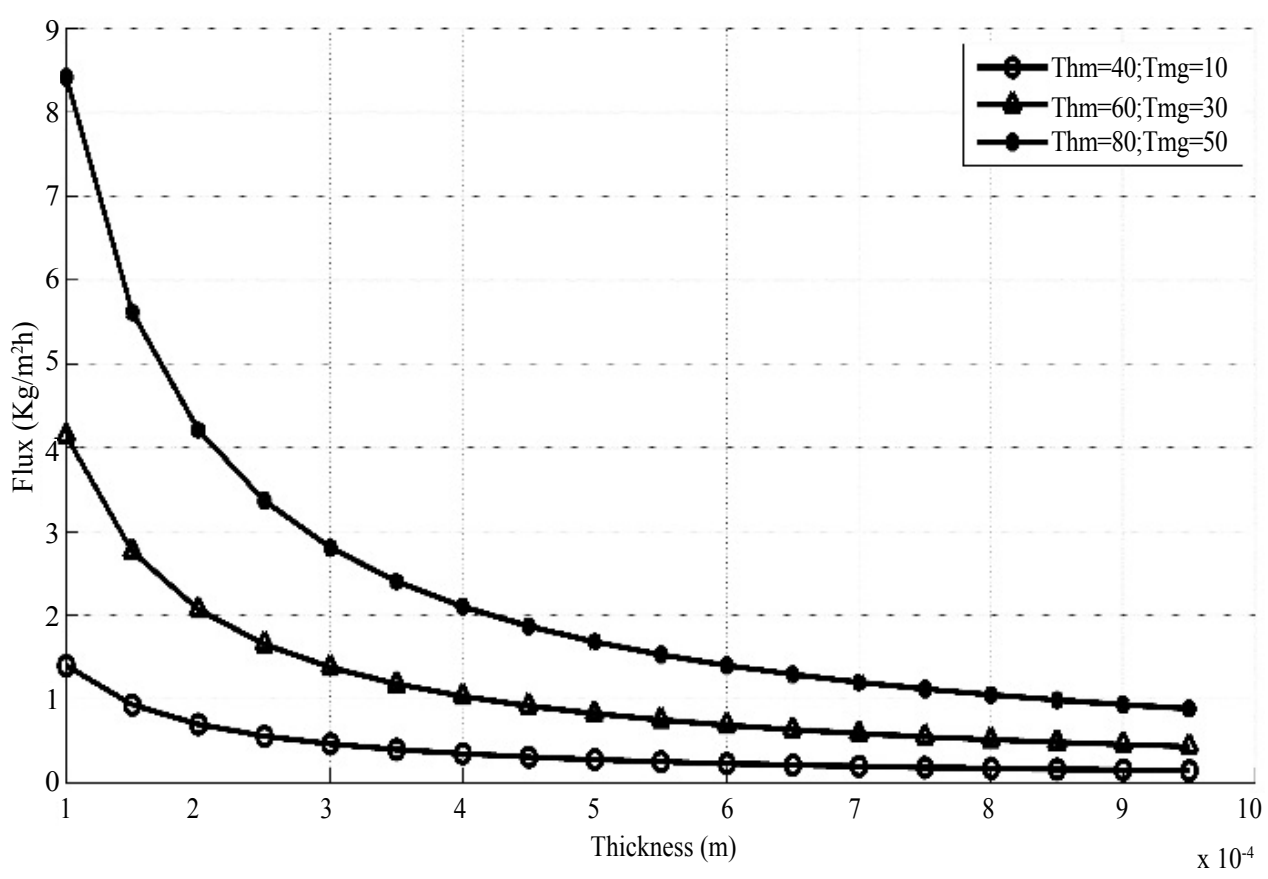

Figure 9: Evolution of model "KMT" as Function of membrane Thickness in three different temperatures.

This equation reflects the diffusion of molecules in a porous and homogeneous system. $C_{1}$ and $C_{2}$ are the concentrations of both sides of the membrane, $\mathrm{K}$ is the transfer coefficient, $\delta_{\mathrm{m}}$ is the thickness of the porous membrane.

Figure 10 shows the variation of heat conduction as function of the membrane thickness. In this figure, the heat conduction decreases by increasing the thickness. Furthermore, the flow begins to decrease from the value $\left(1.10^{-4}\right)$ and become constant when the value of the thickness of the membrane exceeds $\left(8.10^{-4} \mathrm{~m}\right)$, the maximum value of heat conduction is about $\left(1,7.10^{7} \mathrm{~kg} / \mathrm{m}^{2} . \mathrm{s}\right)$. This result is logical because the heat conduction decreases gradually depending on the distance of the heat flow because losing the temperature; it also loses the capacity to conduction.

Figure 11 shows representative results on the variation of latent 


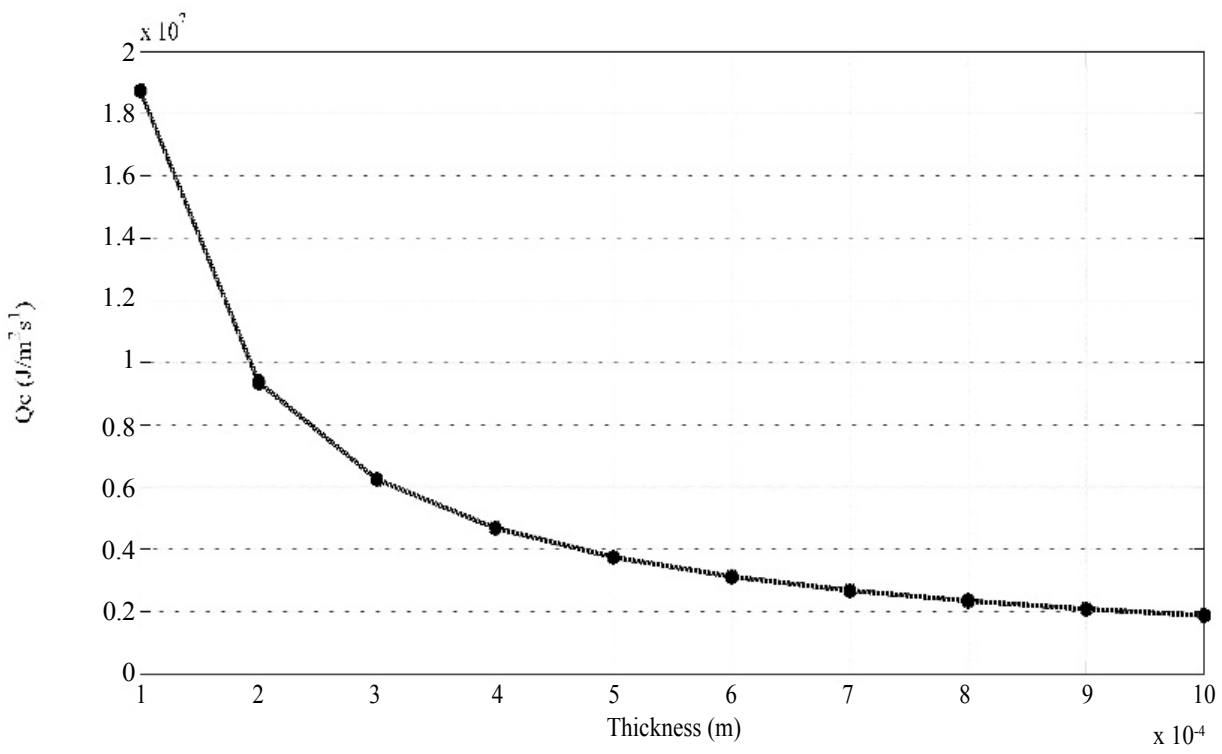

Figure 10: Evolution of the conductive heat as a function of the thickness of the membrane.

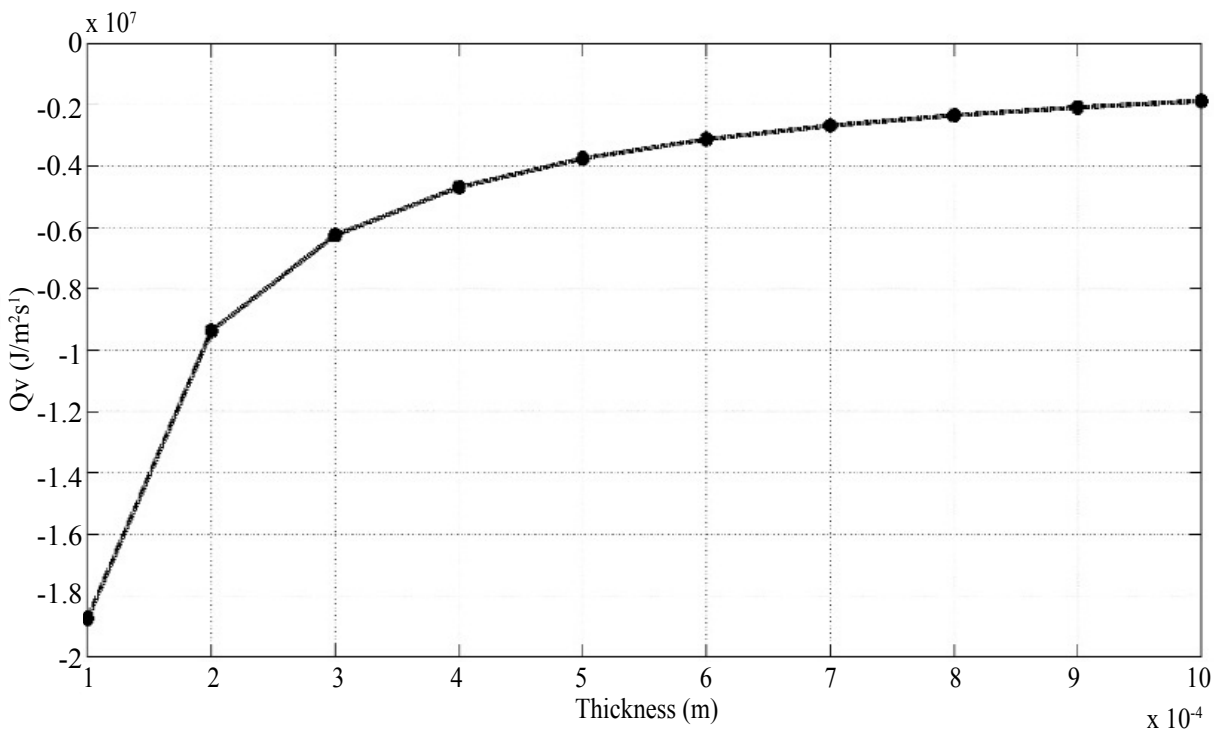

Figure 11: Evolution of the Latent heat as a function of the thickness of the membrane.

heat as function of the membrane thickness. In this figure, a latent heat increases simultaneously with the increase of the thickness of the membrane of $\left(1.10^{-4} \mathrm{~m}\right)$ to $\left(8.10^{-4} \mathrm{~m}\right)$ and became constant when the value of the thickness of the membrane exceeds $\left(8.10^{-4} \mathrm{~m}\right)$. This result is logical because latent heat is released when there is a change of state from, and it has a negative sign because we pass from fusion to condensation.

Figure 12 shows transfer of total heat as function of the membrane thickness. At first, the total heat remains constant up to the thickness $\left(9.10^{-4} \mathrm{~m}\right)$ because of compensation of two values of the heat (latent and conduction), then it will increase when the value exceeds $\left(9.10^{-4} \mathrm{~m}\right)$.

\section{Conclusion}

The broad trends can be summarized as follows, the changes of the steam flow as function of the thickness of the membrane for different flow transfer mechanisms is studied. For both mechanisms Knudsen and viscous, a rating decrease of flux depending on the membrane thickness is observed. For the Molecular mechanism, it is observed, that the flow increases simultaneously with the thickness of the membrane. Later, the thickness of the membrane is varied in various possible combinations of flux transfer mechanism (DGM, Schofield, KMPT, and KMT), an increase of the flow is detected in the model (DGM, Schofield, KMPT) and a stream rating decrease in the model (KMT). We conclude that the flow increases simultaneously with temperature. Finally, before concluding, it is worthwhile to make an observation regarding the Molecular model, DGM model, KMPT model, and Schofield model are not affected by the membrane's thickness. These results were the same conclusion that Mandiang results because the 
Citation: Rochd S, Zerradi H, Mizani S, Dezairi A, Ouaskit S (2016) Modelisation of Membrane Distillation: Mass and Heat Transfer in Air Gap Membrane Distillation. J Membra Sci Technol 6: 154. doi:10.4172/2155-9589.1000154

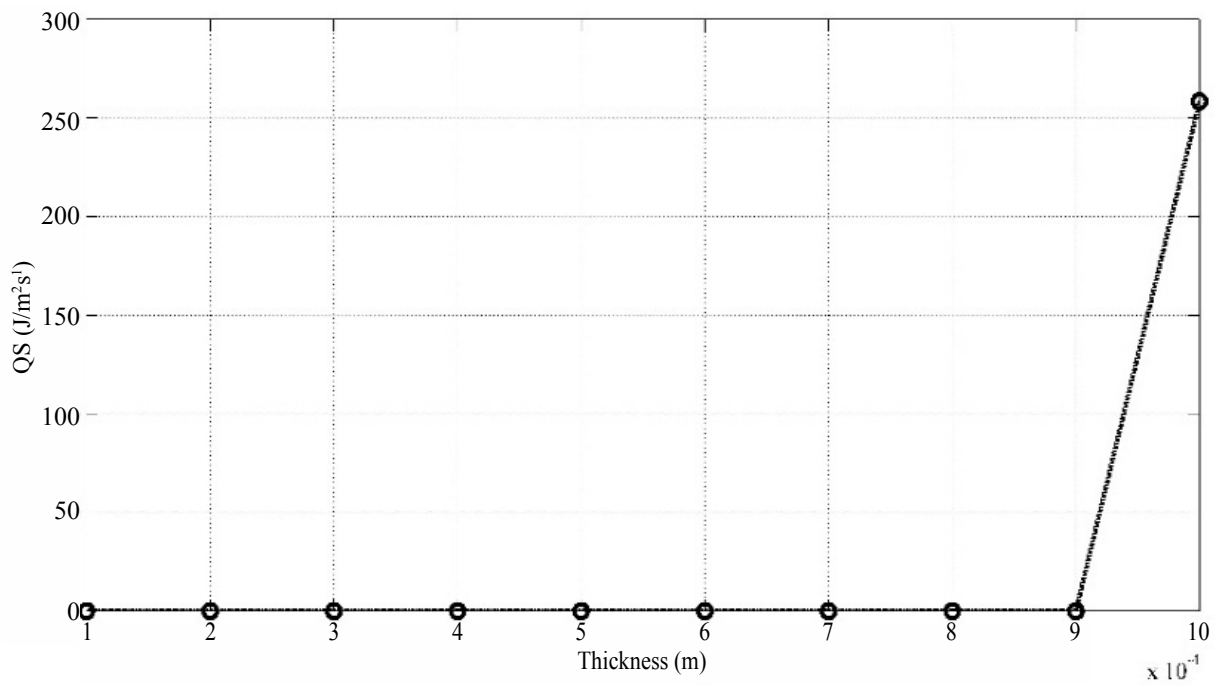

Figure 12: Evolution The total transfer of heat as a function of the thickness of the membrane.

model of Schofield and molecular mechanisms are the most suitable and beneficial for this system. Otherwise, we find that the heat conduction simultaneously decreases depending on the thickness, unlike the latent heat increases by increasing the thickness of the membrane.

\section{References}

1. El-Bourawi MS, Ding Z, Ma R, Khayet M (2006) A framework for better understanding membrane distillation separation process. J Membr Sci 285: 4-29.

2. Lawson KW, Lloyd DR (1997) Review Membrane distillation. J Membr Sci 124: $1-25$

3. Lawson KW, Lloyd DR (1996) Membrane distillation. II. Direct contact MD. J Membr Sci 120: 123

4. Martinez L, Florido-Diaz FJ (2001) Theoretical and experimental studies on desalination using membrane distillation. Desalination 139: 373.

5. Phattaranawik J, Jiraratananon R (2001) Direct contact membrane distillation: effect of mass transfer on heat transfer. J Membr Sci 188: 137.

6. Jonsson AS, Wimmerstedt R, Hanysson AC (1985) Membrane distillation-A theoretical study of evaporation through microporous membranes. Desalination 56: 237.

7. Banat $F$ (1994) Membrane distillation for desalination and removal of volatile organic compounds from water, Ph. D. Dissertation, Mc Gill University, Montreal, Canada

8. Bandini S, Gostoli C, Sarti GC (1992) Separation efficiency in vacuum membrane distillation. J Membr Sci 73: 217

9. Sarti GC, Gostoli C, Bendini S (1993) Extraction of organic comportments from aqueous streams by vacuum membrane distillation. J Membr Sci 80: 21

10. Basini L, D’Angelo G, Gobbi M, Sarti GC, Gostoli C (1987) A desalination process through sweeping gas membrane distillation. Desalination 64: 245.

11. Khayet M, Godino P, Mengual JI (2000) Nature of flow on sweeping gas membrane distillation. J Membr Sci 170: 143.

12. Khayet M, Godino P, Mengual Jl. Theory and experiments on sweeping gas membrane distillation. J Membr Sci 165: 261.

13. Rivier CA, Payo GMC, Marison IW, Stocker VU (2002) separation simulations. J Membr Sci 201: 1.
14. Payo GMC, Rivier CA, Marison IW, Stocker VU (2002) Separation of binary mixtures by thermostatic sweeping gas membrane distillation. II. Experimental results with aqueous formicacid solutions. J Membr Sci 198: 197-210.

15. Alkalibi AM (2008) The potential of membrane distillation as a stand-alone desalination process. Desalination 223: 375-385.

16. Alkalibi AM, Lior N (2005) Transport analysis of air gap membrane distillation J Memb Sci 255: 239-253.

17. Ding Z, Ma R, Fane AG (2002) A new model for mass transfer in direct contact membrane distillation. Desalination 151: 217-227.

18. Meindersma GW, Guijt CM, De Haan AB (2006) Desalination And water recycle by Air Gap Membrane Distillation. Desalination 187: 291-301.

19. Guijt CM, Meindersma GW, Reith T, De Haan AB (2005) Air Gap Membrane Distillation: Separation and purification Technology 43: 233-244.

20. Gil MAI, Payo MCG, Pined CF (1999) Air Gap Membrane Distillation of Surcrose solutions. J Memb Sci 155: 291-307.

21. Chouikh R, Bouguecha S, Shahbi M (2005) Modeling of a Modified Air Gap Distillation Membrane for the Desalination of Sea water 181: 257-265

22. Mandiang Y, Sene M, Thiam A (2015) Mathematical Modeling And Simulating of coupling parameters Transfers of Steam In A Membrane-Type Solar Still Agmd. J Materiel Sci Eng 4: 1-13.

23. Asghari M (2015) Desalination. 374: 92-100

24. Mandiang Y, Sene M, Thiam A, Azilinond (2015) Daily Estimate of Pure water in a desalination Unit by Solar Membrane Distillation. J Materiel Sci Eng 4: 170.

25. Ding Z, Ma R, Fane AG (2002) A new model for mass transfer in direct contact membrane distillation. Desalination 151: 217-227.

26. Qtsaishat M, Matsuura M, Kruczek B, Khayet M (2008) Heat and mass transfer analysis in direct contact membrane distillation Desalination 219: 272-292.

27. Sene M, Mandiang Y, Azilinon D (2013) Hybrid Technology Solar Therma Membrane Desalination of Salt Water for Populations In The Saloum River Delta. Int. Journal of Engineering Research and Application 3: 1091-1102.

28. Fahmi A, Al-Rub A, Banat F (2003) Sensitivity analysis of air gap membrane distillation. SciTechnol 38: 3645-3667.

29. Truskey GA, Yuan F, Katz DF (2004) Transport Phenomena in Bioloigical Systems. NJ Paerson Prentice Hill. 